\title{
Challenges of Home Treatment/Care of COVID-19 Patients in Nigeria: A Public Health Risk and a Huge Deceit of our Time
}

\section{Azuonwu $0^{1 *}$, Ama-Okachi BC ${ }^{1}$ and Chuku $\mathrm{EC}^{2}$}

${ }^{1}$ Department of Medical Laboratory Science, Medical Bacteriology/Virology/Parasitology Unit, Rivers State University, Nkpolu-Oroworukwo, Port Harcourt, Nigeria

${ }^{2}$ Department of Applied and Environmental Biology, Rivers State, University, Nkpolu OroWorukwo Port Harcourt. Nigeria

\section{Research Article}

Volume 5 Issue 5

Received Date: October 29, 2020

Published Date: December 09, 2020

DOI: $10.23880 /$ oajmb-16000179

*Corresponding author: Azuonwu, Obioma, Department of Medical Laboratory Science, Medical Bacteriology/Virology/Parasitology Unit, Rivers State University, Nkpolu-Oroworukwo, Port Harcourt, Nigeria, Tel: +234 8035519688; Email: bimajacobs@yahoo.co.uk

\section{Abstract}

Background: Coronavirus disease-2019 was first discovered in a highly populated city of China in late 2019, and has since spread to most countries of the world, causing several morbidities and mortalities. In the bid to contain the disease and curtail its spread, different countries have instituted several policies, and while these policies may work for some countries, it may not work for others. Nevertheless, the disease has affected over 19 million people globally, killing as many as 700,000. Yet, thousands of persons are still being infected on a daily basis.

Aim: To x-ray and evaluate the suitability of home-based treatment/care of COVID-19 patients in Nigeria.

Methodology: Peer-reviewed articles revealing information about COVID-19 and its effects globally were sourced from different electronic databases (including WHO, Pub Med, Science Direct, NCDC, etc.), and appraised to extract valuable data and information from them for the purpose of analysis and synthesis of developing robust body of knowledge.

Findings: The results obtained from our search include some details about COVID-19 infection, the disease epidemiology, diagnosis, management and guidelines for home-based treatment of COVID-19 patients. Also, discussed in this study are some loopholes in the Nigerian health system and leadership that makes it difficult for foreign policies or strategies (on COVID-19 containment) to be implemented in Nigeria.

Conclusion/Recommendation: Differences in lifestyles and cultures among different countries of the world means that there is no one-size-fits-all solution to the problems created by the emergence of the COVID-19 pandemic. Hence, each country is advised to determine which policies best suit the lifestyles and cultures peculiar to her inhabitants. There is literally no room for copy and paste syndrome

Keywords: Home Treatment; COVID 19 Patients; Poor Leadership and Corruption; Poor Housing; Lack of Health Infrastructure; Poor Hygiene

Abbreviations: WHO: World Health Organization; SARSCov-2: Syndrome Coronavirus 2; Hcws: Healthcare Workers; R0: Reproductive Number; PPE: Personal Protective Equipment; Rrt-PCR: Real-Time Reverse-Transcription
Polymerase Chain Reaction Tests; Rdrp: RNA Polymerase; ORF: Open Reading Frame; HRP: Horseradish Peroxidase; CPAP: Continuous Positive Airway Pressure; PBW: Predicted Body Weight; GPS: Global Positioning System. 


\section{Open Access Journal of Microbiology \& Biotechnology}

\section{Introduction}

Coronavirus disease 2019 (also known as COVID-19) first broke out in Wuhan City, Hubei Province, China in December 2019 [1]. It then spread around the world in a short space of time, causing many countries of the world to institute either a partial or a complete lockdown in order to curtail the spread of the virus [2,3]. The World Health Organization (WHO), on $30^{\text {th }}$ January 2020 , labeled the causative virus as Severe Acute Respiratory Syndrome Coronavirus 2 (SARS-CoV-2), and as a result of its rapid spread around the world, the WHO also declared it a "public health emergency of international concern" [4,5]. Between December 2019 and March 2020, the disease had already spread to 114 different countries around the world, affecting over 118,000 people. As a result, the WHO described the outbreak as a pandemic [6].

The first case of the disease in Africa was recorded in Egypt on $14^{\text {th }}$ February 2020 [7] and has spread to every country in the continent, disrupting their economic activities in diverse ways [8]. The index case in Nigeria was recorded on $27^{\text {th }}$ February 2020 and has also spread to all the states in the country $[9,10]$. Following the increasing spread of COVID-19 in Nigeria, the federal government instituted a lockdown in some states to help curtail the spread. The lockdown legislations only but helped increase the level of poverty and hunger in the country, prompting many citizens to disobey the lockdown order in the hope of making sales or working to earn money via other services to survive, but only to get apprehended by the police [9].

Uninterestingly, a lot of employed people were laid off from their jobs as COVID-19 incapacitated their employers [11]. A lot of businesses such as hotels, bars, and clubs were placed on lock and key, cost of logistics for businesses hiked, the outputs, revenues and profits of businesses reduced, cost of goods and services (including food) increased, and it was predicted that Nigeria may be facing her worst unemployment crisis since her independence [11]. Sadly, many Nigerians have continuously doubted the existence of COVID-19, accusing the government of subjecting the poor masses to increased hardship in order to loot more money to enrich themselves [12].

Furthermore, the response from the health sector to the disease in terms of diagnosis, treatment/care and contact tracing has not been up to standard. The inadequate testing capacity in the country [13] means that those in remote areas of the country may not have access to COVID-19 tests. People who are isolated in isolation centres have continuously attempted to escape from the centres, and many have succeeded in fleeing, depicting the lack of trust in the health system [14]. Recently, the federal government has implemented home treatment of COVID-19 in Nigeria, amidst all the shortcomings ranging from lack of basic infrastructure and critical social amenities that would promote family and personal hygiene in our homes, even when awareness of health education outcomes, remains very skeletal among the vulnerable subjects in the cities and remote communities of Nigeria.

\section{Justification of the Study}

Nevertheless, COVID-19 cases, deaths and the rate of disease transmission in Nigeria keep rising by the day, despite the scary but skeletal interventions, made by the government and her non-formidable health agencies in the country [10]. In the course of the past months, since the first case of the disease was reported in the country, the government of Nigeria has adopted several policies being explored in other countries to mitigate the disease spread and contains the illness. Such policies include lockdown legislations, temporary closure of schools, churches, markets and businesses, cancellation of international flights, with the most recent being the implementation of home treatment/ care for COVID-19 patients $[15,16]$. However, not much evidence-based research has been done to evaluate the suitability of certain policies being adopted by the Nigerian government to fight COVID-19 in the country. Hence, this work would attempt to evaluate the feasibility, challenges and effectiveness of home-based treatment option of COVID-19 patients in the country, by comparing the situations in other countries with respect to presence of basic health infrastructure, commitment strategies and availability of trained and re-trained public health expertise and robust health education awareness outcome among her citizens vizp-a-viz of what is tenable in the developed communities of the globe. However, it is therefore firmly believed that data generated in the end would be evidence based, succinct and useful towards guiding Nigeria government and her health agencies on how to implement the framework, so as to achieve the much desired goals, thus looking at the community based solutions that are indigenous and cultural to the lifestyle of the people, may be the best appropriate options, than adopting foreign policies hook line and sinker without conscious considerations of visible variations between the developed and the underdeveloped communities of the world.

\section{Methodology}

\section{Study Approach}

This study is a systematic review of selected and published articles that follows the sequence of systematic review, as described by Aveyard [17]. This sequence involves the extraction of the detailed summary of valid research evidence applicable to other studies, and presentation of this 


\section{Open Access Journal of Microbiology \& Biotechnology}

detailed outcome after it has been critically assessed by a given body of knowledge.

\section{Strategy and Search Items}

Several keywords, as well as the different ways to describe this topic, were obtained from a quick Google search and these were used to search through various electronic databases such as WHO, Science Direct, Pub Med, NCDC, CDC, BBC, UNESCO and Lancet. For each of the articles retrieved, the abstract was assessed to identify its focus and determine its relevance to the topic being reviewed. The combination of different Boolean operators with various keywords also helped us to generate more hits on the search generally.

\section{Inclusion and Exclusion Criteria}

The articles included in this study are peer-reviewed articles which were published in English language, providing detailed information on COVID-19 infection and SARS-CoV-2 around the world and in Nigeria, as well as other research articles providing information about the various guidelines on how to manage the disease. On the other hand, articles not providing the above-listed information were excluded.

\section{Data Extraction and Methodological Quality of the Included Studies}

Certain criteria such as validity, source reliability, design frameworks, findings generalizability and simplicity of information were employed to determine the methodological quality of the included articles. Individual appraisal of all the sourced articles was carried out before the findings were presented.

\section{Findings}

The search on the various electronic databases yielded results which include some details about COVID-19 infection, the disease epidemiology, diagnosis, management and guidelines on home-based care for COVID-19 patients. It was also established that a policy that may work for a country may not work well in another country as a result of the differences in lifestyles, level of hygiene, health education and cultures barriers and variations.

\section{COVID-19}

COVID-19 is a pandemic disease that has affected millions of people around the world, as well as economies, causing a large number of illnesses and deaths globally $[18,19]$. It is an infectious disease of the respiratory tract caused by a newly discovered strain of coronavirus. Most patients with this disease experience mild to moderate respiratory illness and do not require any special treatment to recover. However, elderly people and those with underlying health conditions like chronic respiratory disease, diabetes, cardiovascular disease and cancer are more susceptible to serious/severe illness resulting from COVID-19 [20].

COVID-19 is caused by a novel coronavirus known as severe acute respiratory syndrome coronavirus 2 (SARSCoV-2). It is a single-stranded, enveloped, non-segmented, positive-sense RNA virus with a genome size of $29.9 \mathrm{~kb}$, and belongs to the beta coronavirus genus of viruses $[21,22]$. This is the seventh human-susceptible coronavirus known, with the others including $\mathrm{HCoV}-229 \mathrm{E}$ and $\mathrm{HCoV}$ NL63 ( $\alpha$-coronaviruses), HCoV-HKU1 and HCoV-OC43 ( $\beta$-coronaviruses) all of which causes mild respiratory illnesses resembling a common cold; the other two are SARS$\mathrm{CoV}$ and MERS-CoV (Middle East respiratory syndrome coronavirus), both of which can cause potentially fatal severe respiratory tract infections [23].

Nevertheless, it has been recorded that SARS-CoV-2 shares about $79.5 \%$ similarity in genomic sequence with SARS-CoV, and about 96.2\% similarity with RaTG13 (bat coronavirus). Bats have been suspected to be the natural hosts for SARSCoV-2 on the basis of virus genome sequencing results and evolutionary analysis. Transmission via unknown intermediate hosts from bats to humans has also been suggested. According to research, SARS-CoV-2 can gain entry into human tissues via the angiotensin-converting enzyme 2 (ACE-2) receptor in tissues (the same receptor used by SARS-CoV) to cause the illness [24].

\section{Epidemiology}

COVID-19 first broke out in Wuhan, Hubei Province, China in December 2019, and has since spread like wildfire around the world, affecting over 32 million people and killing over $990,000[25,26]$. The infection is less frequently observed in children, and they (children) manifest milder symptoms when compared to adults. Children, globally, are also less likely to be tested as a result of the mild presentation of disease [27]. A nationwide case series conducted in China, which comprised 2,135 paediatric cases, showed that only $34.1 \%$ of the cases were confirmed in the laboratory and $4.4 \%$ of the children were asymptomatic [28]. According to several studies, mild disease occurs in $10-60 \%$ of children, chiefly presenting as a febrile disease of the upper respiratory tract. Children tend to experience milder and shorter course of the disease, with mild gastrointestinal and/or respiratory symptoms. However, cases of severe disease have also been reported [27]. According to reports from China, $2.5-5 \%$ of paediatric cases had severe disease $[28,29]$. A systematic review from China reported that $39-82 \%$ of patients had a moderate course of the disease and mild pneumonia, 


\section{Open Access Journal of Microbiology \& Biotechnology}

whereas, severe course of the disease and even deaths were recorded in about $8 \%$ of the hospitalized patients [30]. Also, in China, an early analysis revealed that children suffering from critical illness accounted for only less than $1 \%$ of the reported cases [29,31]. In the US, data obtained revealed the hospitalization of $5.7 \%-20 \%$ of paediatric cases, of which the majority were infants [32]. A study across Italy, which involved 11 explicitly paediatric hospitals and 51 paediatric units, revealed an inverse relationship between hospital admission and age ( $<<0.01$; Fisher exact test) [33].

Pregnant women usually experience mild clinical manifestations, and only a few severe diseases and fatal outcomes have been reported Dong XC, et al. [34,35]. A systematic review revealed that the clinical presentations and severity of COVID-19 in pregnant women are similar to the disease manifestations observed in other non-pregnant adults [36]. A high percentage of asymptomatic cases exist among pregnant women in different countries. In New York, two studies reported asymptomatic in $87.9 \%$ Sutton D, e al. [37] and 32.6\% [38] of pregnant women with positive RTPCR results for COVID-19 virus at admission for delivery. Such outcomes have been reported in China (65. 2\%) Wu X, et al. [39] and Sweden (7\%) [40].

Vertical transmission of the disease cannot be ruled out, as positive RT-PCR results from placental samples have been recorded, though without the infection of the neonates $[41,42]$. A case report from Iran revealed positive RT-PCR results in the amniotic fluid and the nasopharyngeal swabs of the neonate (obtained $24 \mathrm{hrs}$ after birth), and negative results from the vaginal secretion and umbilical cord blood of the mother and the neonate's nasopharyngeal swabs (obtained immediately after birth) [43]. Also, two studies recorded elevated levels of IgM and IgG antibodies against SARS-CoV-2 in neonates born to COVID-19 positive mothers $[44,45]$. Nonetheless, there is a paucity of data to evaluate the role of breastfeeding in COVID-19 transmission [45- 48]. Just one study has recorded positive RT-PCR results in the breast milk of a positive mother [49]. Her baby also tested positive, but the exact mode of transmission remained uncertain [49].

Furthermore, healthcare workers (HCWs) are also at a high risk of COVID-19 infection as they are more frequently exposed to COVID-19 cases, and may be involved in the spread of the illness in healthcare institutions [50]. A study in the US and the United Kingdom estimated that healthcare workers in the frontline had up to a 3.4-fold higher risk of contracting COVID-19 than people living in the general community, and are more likely to be tested [51]. Also, disease severity in HCWs may be influenced by their exposure to higher virus concentrations (especially from severely ill patients) [52]. However, the elderly and those with underlying health conditions are more susceptible to serious illness [20].

The average number of secondary infections that can result from a single infection (Reproductive number (R0), as reported by a review of 12 modeling studies based on statistical and stochastic methods, is 3.28 , with a median of 2.79 [53,54]. Whereas, the median incubation period for the virus, according to current estimates, is from five to six days, with the incubation ranging from 2 to 14 days. Some modeling studies have suggested that the incubation period can be from 2.3 days ( $95 \%$ CI, 0.8-3.0 days) before the onset of symptoms, and up to 14 days $[55,56]$.

The disease has spread to most regions of the world, including Africa, The Americas, Eastern Mediterranean Region, Europe, South-East Asia and the Western Pacific Region [20]. In Nigeria, the disease has spread to all 36 states, as well as the federal capital territory (Abuja) [10]. It has also been reported that not less than 812 healthcare workers across the country had been infected with the disease as of 2 June 2020 [57] (Figures 1-4).

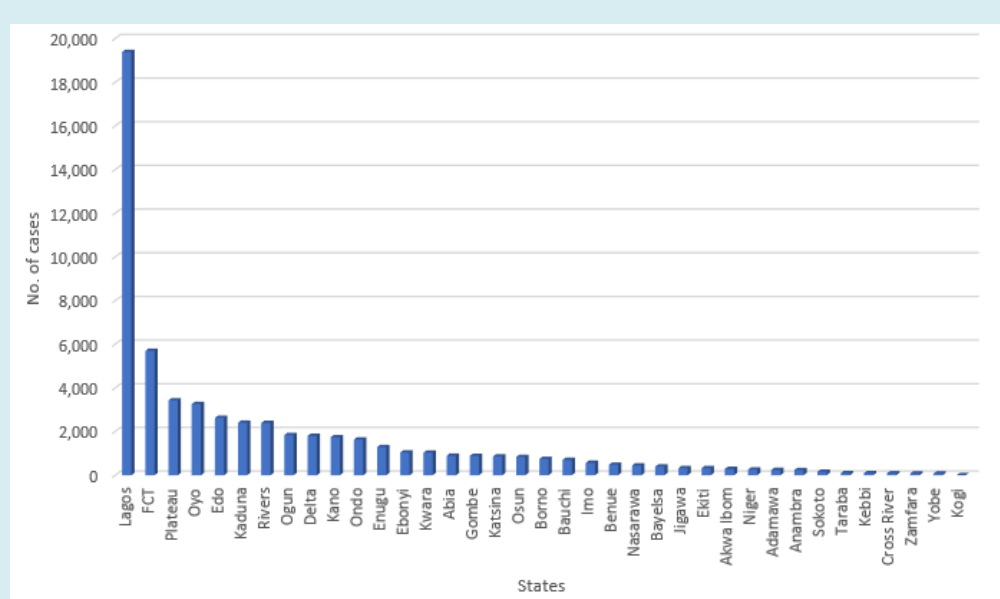

Figure 1: Number of COVID-19 .Cases in Nigeria by States as of 30 September 2020 [10]. 


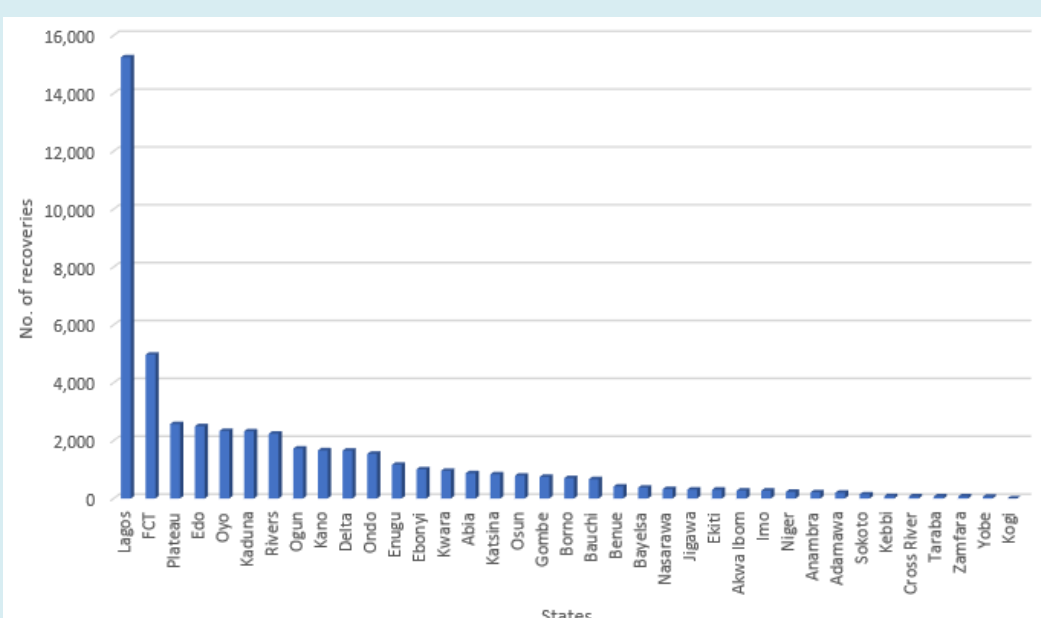

Figure 2: Number of COVID-19 Recoveries in Nigeria by States as of 30 September 2020 [10].

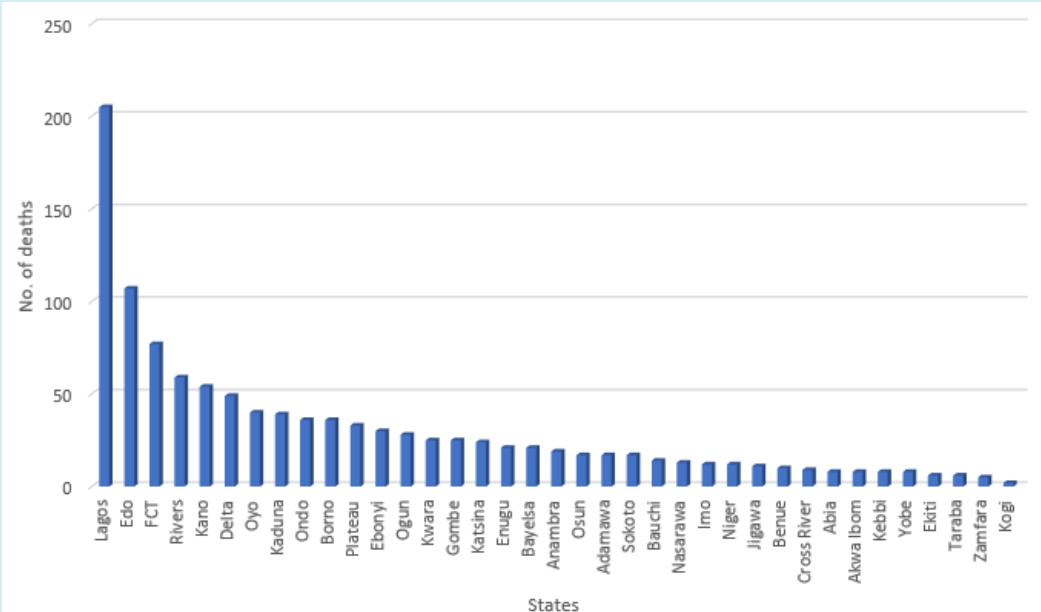

Figure 3: Number of COVID-19 Deaths in Nigeria by States as of 30 September 2020 [10].

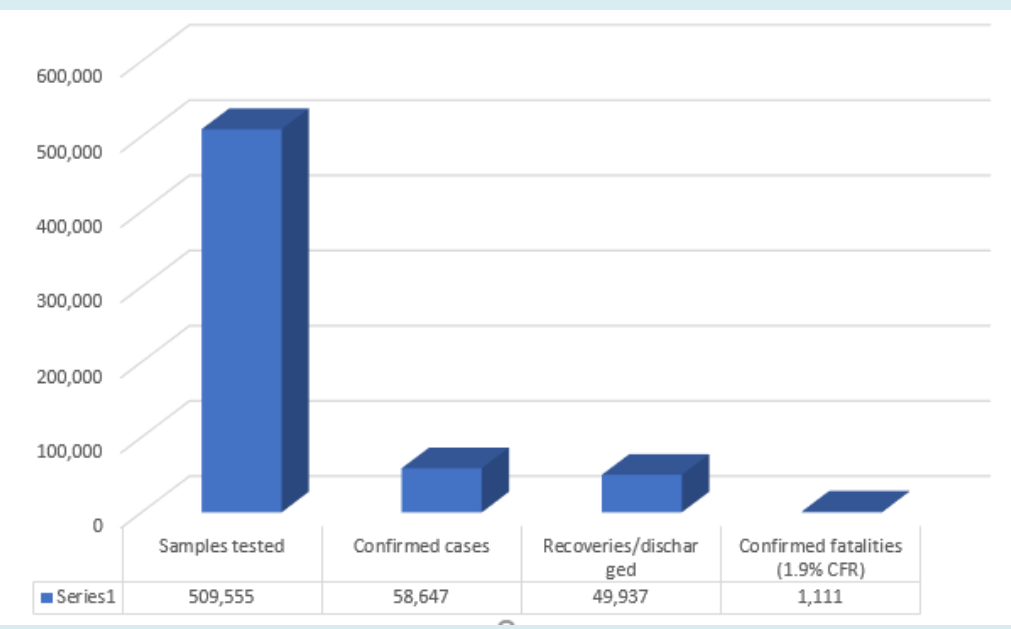

Figure 4: Details of COVID-19 Cases in Nigeria as of 30 September 2020 [10]. 


\section{Open Access Journal of Microbiology \& Biotechnology}

\section{Community Transmission of COVID-19}

According to the WHO, community transmission of COVID-19 ensues when it becomes difficult or impossible to relate a large number of confirmed cases through chains of transmission, or when there are an increasing number of positive tests through sentinel samples [58]. In other words, it ensues when the source of origin of the infection in a new community cannot be traced, and who got infected by an interaction with an infected patient cannot be identified [59]. The increase in community transmission in Nigeria underscores the increased need for social distancing, as well as a compromise in some government activities [60].

\section{Secondary Transmission of COVID-19}

COVID-19 spread to individuals from cases which have been exposed to the original source of infection is regarded as secondary transmission [61]. There is a relatively low risk of secondary transmission among close contacts of people diagnosed with COVID-19 (less than 4\% overall), and according to new research, this varies by settings and disease severity of index cases [62]. A study conducted in China revealed an overall secondary attack rate (SAR) of $3.3 \%$ (95\% CI 1.9\%-5.6\%). Of these, for household contacts, the SAR was $16.1 \%, 1.1 \%$ for social contacts and none were recorded in workplace contacts. In terms of age, the highest SAR was recorded in older close contacts $>60$ years of age (8.0\%), while $1.4 \%-5.6 \%$ was recorded in persons $<60$ years of age. The lowest SAR was recorded in close contacts of asymptomatic index case-patients $(0.8 \%)$. Whereas, a $3.5 \%$ SAR was recorded in the close contacts of patients with mild symptoms, $5.7 \%$ for patients with moderate symptoms, and $4.5 \%$ for patients with severe symptoms [63].

\section{COVID-19 Risk Factors}

COVID-19 is a disease that can affect anyone and can cause various symptoms ranging from mild to critical. However, some people may have higher chances of experiencing severe illness than others because they possess some characteristics or medical conditions that make them more vulnerable. These are collectively known as "risk factors" [64]. The most common risk factors include older age and the presence of certain underlying medical conditions. Whereas, other risk factors include pregnancy, certain occupations, race/ethnicity, use of certain medications, gender, smoking, poverty and crowding [65]. Furthermore, the risk factors among healthcare workers include lack of personal protective equipment (PPE), work overload, exposure to infected patients, poor infection control and preexisting medical conditions [66].

\section{Diagnosis SARS-CoV-2 Infection}

\section{Direct Diagnosis}

The direct diagnosis COVID-19 directly involves the detection of COVID-19 virus (SARS-CoV-2) RNA on nasopharyngeal swabs or specimens from the lower respiratory tract [67]. The former is the most widely used in clinical practice, whereas, tests on specimens from the lower respiratory tract are performed in some defined cases [67]. In some patients, especially those with a good outcome, viral RNA can be detected in their specimens for as long as 20 days or more following the onset of symptoms. Even after the viral RNA is no longer detectable with PCR, a rebound of the viral load is still possible [68]. Comparatively, the detectability of SARS-CoV-2 RNA by rt-PCR peaked for specimens of upper respiratory tract at 7-10 days following the onset of symptoms and then declined steadily; whereas, rt-PCR RNA detection in specimens of the lower respiratory tract remained stable for 21 days following symptom onset/ clinical presentation [68].

\section{Real-Time Reverse-Transcription Polymerase Chain Reaction Tests (rRT-PCR)}

The most used test for SARS-CoV-2 RNA detection is the rRT-PCR test [67]. In rRT-PCR tests, the primers are designed against several structural targets of the virus such as the envelope (E) and RNA-dependent RNA polymerase (RdRp) regions [69]. The E-region is the target for first-line screening, while the RdRp region is targeted for confirmatory testing. Some other researchers also developed one-step RT-PCR assays to detect some other structural targets like the open reading frame (ORF) $1 \mathrm{~b}$ and $\mathrm{N}$ regions of SARS-CoV-2 [70]: The $\mathrm{N}$ region assay is employed for screening, while ORF1b region is targeted for confirmatory testing. However, since Sarbecoviruses are endowed with ORF1b and N regions, there is the tendency of the specific primers binding to other coronaviruses and closely related viruses [71].

Nonetheless, due to the several cases of false-negative results being reported [72-75], it has been reported that a negative result does not exclusively rule out SARS-CoV-2 infection. Hence, rRT-PCR should not be used as a lone test for clinical management [71].

\section{Reverse-Transcription-Loop-Mediated Isothermal Amplification (RT-LAMP)}

RT-LAMP has been widely employed for the rapid detection of virus-specific genes in recent times, and its specificity and sensitivity are comparable to those reported 


\section{Open Access Journal of Microbiology \& Biotechnology}

for rt-PCR assays. This assay involves the use of a constant temperature to exponentially amplify specific nucleic acid sequences [76]. LAMP can be combined with reverse transcription (rt-LAMP) to allow for the direct detection of RNA (including SARS-CoV-2 RNA). In a small study conducted by Wui, et al. it was reported that the results obtained from tests with RT-LAMP method were consistent with those from the conventional RT-PCR [77].

\section{Antigen-Based Tests}

In this assay, a double-antibody sandwich enzymelinked immunoassay can be used to identify SARS-CoV-2 nucleoprotein by the use of a microplate pre-coated with specific antibodies that target SARS-CoV-2 nucleoprotein, and a secondary antibody labeled with horseradish peroxidase (HRP) against the same protein. This method does not require trained personnel or expensive laboratory instruments, as it is simple and rapid to carry out. However, a meta-analysis by Castro, et al. [78] revealed a sensitivity of $70-86 \%$ and a specificity of $95-97 \%$. Hence, a single negative test result cannot exclude SARS-CoV-2 infection.

\section{Indirect Diagnosis}

Indirect diagnosis of COVID-19 is based on the detection of the virus-specific IgG and/or IgM antibodies. The WHO had earlier highlighted that serological IgM and IgG testing, as well as a quick design of easy and inexpensive point-ofcare tests, are strongly needed to help contain COVID-19 $[29,79,80]$. A study by To et al evaluated the viral load and antibody kinetics on posterior nasopharyngeal samples and has suggested that serological testing may be complementary with RT-PCR testing [71]. Several serological assays have been made available for the detection of the viral proteins and antibodies in serum or plasma samples.

\section{Enzyme-Linked Immune Assay (ELISA)}

ELISA is an assay used to detect anti-SARS-CoV-2 IgG and IgM responses by detecting antibodies against the nucleoproteins and spike proteins of the virus. However, a limitation in the use of this method is the absence of defined standards [71].

\section{Chemiluminescent Immunoassay (CLIA)}

CLIA allows for the quantification of antibodies by utilizing light-producing chemical reactions. In this assay, a substrate reacts with Avidin-Horseradish Peroxidase, resulting in light development, and this allows for the estimation of the IgG and IgM titers by quantifying the amount of the emitted luminous signal [71].

\section{Rapid Serological Tests}

Several rapid IgM/IgG tests (based on immunoassay technology) have been developed, producing results in 10-15 minutes [81]. These devices are made up of murine anti-human IgG antibodies and colloidal gold-labelled SARS$\mathrm{CoV}-2$ recombinant protein immobilized in the $\mathrm{G}$ area, murine anti-human IgM antibodies immobilized in the $\mathrm{M}$ area, and the corresponding antibody in the $\mathrm{C}$ area (quality control area) [71]. However, due to the substandard specificity and specificity levels of these assays as reported by current data, the WHO does not recommend their use for patient care, but has encouraged the continuation of the present work in order to establish their helpfulness in epidemiological research and disease surveillance [67].

\section{Management of COVID-19}

\section{Management of Mild COVID-19}

It is recommended by the WHO that patients with mild COVID-19 be given symptomatic treatment (treatment to help relieve the patient of the symptoms) such as antipyretics for fever and pain, appropriate nutrition and rehydration [82]. There should be close monitoring of patients with risk factors for severe illness due to the possibility of deterioration in their health. Upon the development of any worsening symptoms (e. g. breathing difficulties, chest pain, lightheadedness, dehydration, etc.), the patient(s) should seek immediate care, following the WHO established pathway for COVID-19 care. Also, children with mild COVID-19 should be monitored by their caregivers for signs and symptoms of clinical deterioration that may require urgent re-assessment. Some clinical deteriorations can include breathing difficulties or fast/shallow breathing (grunting and breastfeeding difficulties can be observed in infants), chest pain, blue lips/face, new confusion, drinking difficulties or inability keep down liquids, awakening difficulties or inability to interacting when awake. In addition, alternative care delivery mediums (such as home-based, phone, telemedicine or community outreach teams) should be considered to assist with monitoring [83].

\section{Management of Moderate COVID-19}

As recommended by the WHO, suspected or confirmed cases of moderate COVID-19 (presenting with pneumonia) should be isolated to curtail further transmission of the virus. Emergency interventions or hospitalization may not be required for patients with moderate illness, but isolation is imperative for all suspected or confirmed cases. The choice of the location of isolation should be made on a case-bycase basis and should depend on the clinical presentations, requirement supportive care, potential risk factors for 


\section{Open Access Journal of Microbiology \& Biotechnology}

severe disease, as well as the conditions at home (including the presence of high-risk individuals in the household). However, hospital isolation is preferred for patients at high risk of deterioration [82].

Nonetheless, febrile patients in areas with other feverinducing endemic infections (such as malaria, dengue, etc.), should be diagnosed and treated for such infections regardless of the presence of respiratory signs and symptoms, as co-infections with COVID-19 may occur [84-86].

Furthermore, patients being treated at home and their caregivers should be enlightened on signs and symptoms of complications (e.g. breathing difficulties, chest pain, etc.). Upon the development of any complication(s), urgent care should be sought through the established COVID-19 care pathway. Also, there is usually no evidence to guide the use of pulse oximeters the home. Hence, alternative delivery platforms (such as home-based, phone, telemedicine or community outreach teams) should be considered to support monitoring. Hospitalized patients should be monitored regularly for vital signs (including pulse oximetry); medical early warning scores (e.g. NEWS2, PEWS) which promote early recognition of deterioration and enhancement of treatment for deteriorating patients should be utilized where possible [87].

\section{Management of Severe COVID-19}

All patients with severe COVID-19 infection should be treated and cared for in areas equipped with pulse oximeters, functioning oxygen systems, as well as disposable, single-use oxygen-delivering interfaces (such as Venturi mask, nasal cannula, and mask with reservoir bag). Such areas include areas in any part of health facilities (including critical care units, emergency units, primary care/outpatient clinics), pre-hospital settings and improvised community facilities where patients with severe COVID-19 may be received [82].

As recommended by the WHO, patient with emergency signs (such as obstructed or absent breathing, central cyanosis, severe respiratory distress, coma, shock and/or convulsions) should receive emergency airway management and supplemental oxygen therapy during resuscitation to target $\mathrm{SpO}_{2} \geq 94 \%$; the same should be administered to patients without emergency signs but with $\mathrm{SpO}_{2}<90 \%$. Once the patient is in a stable state, an $\mathrm{SpO}_{2}$ target of greater than $90 \%$ should be maintained in non-pregnant adults and children, while $\mathrm{SpO}_{2} \geq 92-95 \%$ should be targeted for pregnant women [88-90]. The well-being of a foetus should be monitored after the resuscitation and stabilization of the mother. The observations of foetal heart rate should be individualized on the basis of foetal conditions, gestational age and maternal clinical status (e.g. hypoxia) [82]. The WHO also warns against the prescription of antibiotics for patients with suspected or confirmed moderate COVID-19, except there is clinical suspicion of bacterial infection [82].

Furthermore, close monitoring of patients for signs of clinical deterioration (such as rapidly progressive respiratory failure and shock) should be ensured, and followed by an immediate response with effective and safe supportive care interventions once there is deterioration. Also, cautious use of intravenous fluids for treatment should be ensured as aggressive fluid resuscitation may further impair oxygenation (in both children and adults), especially in areas where mechanical ventilation is in limited availability [91].

\section{Management of Critical COVID-19 (Acute Respiratory Distress Syndrome - ARDS)}

For COVID-19 patients with mild ARDS, high-flow nasal oxygen (HFNO) therapy, non-invasive ventilation continuous positive airway pressure (CPAP), and bilevel positive airway pressure (BiPAP) has been recommended by the WHO. When a patient with respiratory distress is not responding to standard oxygen therapy, early recognition of escalating acute hypoxaemic respiratory failure should be ensured, and followed by an adequate preparation to provide advanced oxygen/ventilatory support. The WHO has also recommended endotracheal intubation by a trained and experienced provider (utilizing airborne precautions); administration of mechanical ventilation utilizing lower tidal volumes $(4-8 \mathrm{~mL} / \mathrm{kg}$ predicted body weight [PBW]) and lower inspiratory pressures (plateau pressure $<30$ $\mathrm{cmH2O}$ ); prone ventilation for 12-16 hours per day for adult patients with severe ARDS (PaO2/FiO2 < 150); avoidance of neuromuscular blockade by continuous infusion in patients with moderate to severe ARDS $(\mathrm{PaO} 2 / \mathrm{FiO} 2<150)$ [82].

In addition, for patients with moderate to severe ARDS, higher positive end-expiratory pressure (PEEP) is encouraged over lower PEEP, while ensuring individualization and considering the benefits versus risks. Also, disconnecting a patient from the ventilator, which results in atelectasis, loss of PEEP, and increased risk of infection of health care workers should be avoided. Airway clearance techniques should also be considered for patients with excessive secretions, or difficulties in clearing secretions [82].

\section{Management of Critical COVID-19 (Septic Shock)}

For septic shock in adults, administration of 250-500 $\mathrm{mL}$ of crystalloid fluid as a rapid bolus within the first 1530 minutes is encouraged for resuscitation. However, in resuscitation for septic shock in children, the administration of $10-20 \mathrm{~mL} / \mathrm{kg}$ of crystalloid fluid as a bolus within the first 30-60 minutes is encouraged. Furthermore, fluid 


\section{Open Access Journal of Microbiology \& Biotechnology}

resuscitation may result in volume overload, causing respiratory failure, particularly with ARDS. Hence, reduction or discontinuation of fluid administration is advised when there is no response to fluid loading, or when signs of volume overload emerge (e.g. jugular venous distension, pulmonary oedema on imaging, crackles on lung auscultation, or hepatomegaly). This is vital, especially for patients with hypoxaemic respiratory failure. The use of hypotonic crystalloids, starches or gelatins for resuscitation is highly discouraged [82].

Nonetheless, the administration of vasopressors (in adults) when shock persists during/after fluid resuscitation is recommended. Whereas, in children, administration of vasopressors is recommended if signs of fluid overload develop, or the persistence of the following after two fluid boluses: signs of shock (e.g. as altered mental state); prolonged capillary refill ( $>2$ seconds) or feeble pulses; bradycardia or tachycardia; tachypnoea; increased lactate; mottled or cool skin or petechial or purpuric rash; oliguria persists after two repeat boluses; or failure to achieve agespecific blood pressure targets [92].

\section{Guidelines for Home-based Treatment of COVID-19}

\section{Who should be Treated at Home?}

Due to the burden of COVID-19 and its consequent overwhelming effects on the health care system, hospitalization may not be encouraged for patients presenting with mild illness, except there is the risk of rapid deterioration in the health of the patient [82]. Hence, home treatment/care may be considered for patients with only mild illness, provided that they can be taken care of and followed up by family members. Another scenario where home care can be considered is when inpatient care is unsafe or unavailable, especially when capacity is limited or resources are not sufficient enough to meet the health care service demand [93].

\section{Requirements for Homes to be used for Treatment}

According to the WHO, a home to be used for the treatment of COVID-19 should have an adequate capacity to make it possible for other members of the household to stay in a different room or, or maintain a distance of at least 1 metre from the patient (for instance, sleeping in a separate bed). The home should also be equipped with sufficient quantities of personal protective equipment for the caregivers and medical masks for the patient [82]. It has also been recommended that homes for COVID-19 treatment should be provided with appropriate caregivers and a separate well-ventilated single room where the patient can recover while maintaining sufficient distance with other members of the household $[82,94]$.

Nevertheless, if the home isolation/treatment is a dormitory and a separate room is not feasible (e.g. secondary schools and tertiary institutions), it should be ensured that shared spaces are well ventilated and there should be sufficient room space for other roommates to maintain a two-meter distance from the case. If there is more than one infected case, efforts could be made to cohort the cases together. Also, if it is not possible to physically separate the cases in their own rooms, demarcating the room by hanging a sheet from the ceiling to separate the ill person(s) from others has been recommended. In addition, isolation/ treatment at home should be such that the case would have access to food, drinking water and other supplies throughout the duration of isolation. Stockpiling the required supplies, food and medications may be considered for homes in remote and isolated communities to avoid interruption of the supply [95].

\section{Requirements for Home Treatment}

COVID-19 patients who should receive home treatment/ care should have their movements in the house restricted and should be capable of maintaining respiratory etiquette and hand hygiene, while also being able to monitor their own symptoms [82,95]. Also, the patient should be stable enough to receive home care and adhere to precautions. Appropriate caregivers (family members, friends or health care workers) should be available or easily accessible at home [94].

Furthermore, where there are limited availability caregivers, the case should be able to self-manage and monitor their own symptoms while maintaining hand hygiene and respiratory etiquette. Also, household members who have conditions that increase their risk of COVID-19 complications (e.g. elderly age, immunocompromising conditions or underlying health challenges) should not provide care for the case and alternative arrangements may be necessary. This could include temporarily relocating these individuals or the case outside of the home to a location determined by public health, such as a designated hotel [95].

\section{NCDC Provisional Guidelines for Home Care of Confirmed COVID-19 Cases}

The Nigeria Centre of Disease Control, through its interim guidelines for home treatment/care of COVID-19 cases, has recommended that clinically stable patients who are below 50 years of age, presenting with mild symptoms or are asymptomatic, with normal oxygen saturation (SpO2 $\geq 95 \%$ on room air) and no history of a non-communicable 


\section{Open Access Journal of Microbiology \& Biotechnology}

disease can be treated/cared for at home with mild caution, provided there is sufficient space for optimum self-isolation. Also, clinically stable patients between 50 and 70 years of age who have no history of co-comorbidities, presenting with mild symptoms or are asymptomatic, with normal oxygen saturation (SpO2 $\geq 95 \%$ on room air) can be cared for at home with sufficient space for self-isolation. However, the NCDC discourages home care/treatment for elderly patients, those manifesting with severe symptoms (regardless of the age), those with more than one co-morbidity, those described as high-risk patients by a qualified clinician based a clinical risk assessment, or those in areas lacking adequate facilities for optimum self-isolation (e.g. inadequate home accommodation and inadequacy in the supply chain of vital supplies). Nevertheless, if the condition of a patient being treated at home worsens, the caregivers or household members are urged to immediately notify the State Case Manager via any of the state's hotline numbers, and the patient should be transferred urgently to a designated treatment center [96].

\section{NCDC Guidelines on the use of Personal Protective Equipment (PPE)}

The risk of COVID-19 transmission is ever-present as long as there is contact between patients and healthy subjects. As a result, the NCDC made some recommendations on which PPE is to be worn and which preventive measures are to be taken to reduce the risk of transmission during home-based treatment of COVID-19. The patient is expected to put on a facemask as much as possible, except when sleeping, and also maintain at least a 2-metre distance from the household members and caregivers. Also, a caregiver is expected to put on a medical mask when entering a patient's room, and if direct care is to be administered to the patient, the caregiver should wear gloves and apron (to protect against splashes). Furthermore, a healthcare worker providing direct assistance/care to a patient at home should wear a medical mask, gown Gloves and eye protection [96].

Nonetheless, the NCDC has also recommended that the Case Management team should conduct a risk assessment of the area intended for use for home-based care/treatment of the ill person, follow the treatment procedure provided in the National Interim Guidelines for Case Management of COVID-19, conduct a baseline assessment of the ill person at the start of care, ensure daily communication with the patient throughout the duration of homecare, adopt virtual modes of consultations such as videoconferencing to limit the duration of contact between patients and healthcare workers and educate patients and household members on the significance of respiratory hygiene, hand hygiene, social distancing and basic infection prevention and control measures. Also, the Case Management team should notify the State Case Manager when a patient is due for a re-test (to enhance the decision on how the patient's sample will be collected), conduct re-testing following the National Interim Guidelines for Case Management of COVID-19, and confirm that symptoms have ceased and discharge criteria has been met [96].

The NCDC also mandated the state epidemiologists to ensure that each patient is assigned an epi-number, and followed up from the outset of isolation/home care [96].

\section{Discussion on Fall out Issues}

There is no one-size-fits-all solution to the COVID-19 dilemma around the globe [97], and hence, different nations must take into consideration the various socio-cultural, political, religious and economic situations when adopting the measures being implemented in other countries. Nigeria as a nation is faced with some challenges that are bound to make it difficult for home-based treatment/care for COVID-19 patients to be implemented in the country.

Firstly, African countries have large population sizes when compared to countries of the Western world. According to a research in 2017, African women have 4.5 children on average, whereas, in Asia, the figure is 2.1 children, in Latin America 2.0, in North America 1.9 and in Europe 1.6 [98]. In Europe, as of 2018, there were 1.55 live births per woman (which ranges from 1.23 in Malta to 1.88 in France). The average age at which women have their first childbirth in countries of the European Union (EU) as of 2018 was 29.3 years (a figure that ranged from 26.2 in Bulgaria to 31.2 in Italy). Also, close to half of the children born in the EU in 2018 were firstborn children [99]. Furthermore, in the EU, $47 \%$ of households have one child, $40 \%$ have two children, $13 \%$ have three or more children while $14 \%$ are lone parents [100]. An increasing number of couples in Europe these days stop having children after the first or second child, while many women choose not to have kids at all [101]. On the other hand, as of 2017, the state in the United States of America (USA), with the highest average number of children per family was Utah with 2.32 children per family [102]. However, as of 2019, the average number of people per family in the USA was 3.14 [103], and the average number of kids per family was 2.5 [104]. With these statistics, it is evident that housing in these countries is not much of a problem, and home treatment/care for COVID-19 patients can be carried out more effectively.

Whereas, in Nigeria, the average number of kids per woman is 5.39 [105]. Also, a typical Nigerian society is characterized by numerous polygamous homes and couples having 5-10 kids or even more. The rate of childbirth is even higher among the non-educated and impoverished as 


\section{Open Access Journal of Microbiology \& Biotechnology}

some of the kids are born out of wedlock, some born as a result of unwanted pregnancies while some are born out of the traditional belief that the more the kids, the more the workforce and fighting power. Also, in the Nigerian society, there are numerous numbers of families living in single rooms, or having many kids who all have to dwell in the same room. Bearing in mind that a requirement for home care for COVID-19 patients is the availability of a well-ventilated single room for the patient [82], it is easier to achieve this in countries characterized by monogamous homes and families with few kids. However, in a typical setting of Nigeria where many families live in a single room, if one member of the household should contract COVID-19, it is almost impossible to achieve optimum isolation and social distancing to reduce the risk of spread to the other members of the household. Home treatment may also promote community transmission of the infection as it poses the risk of disease spread to the entire family and member in the neighborhood.

Also, another requirement for home care is that the patient should have access to vital supplies (such as food, water and medications), and if the area is located in a remote region, stockpiling of these supplies have been recommended [95]. However, the high level of unemployment, poverty and suffering in the country $[106,107]$ is not pointing to the achievement of this requirement. In 2018, the World Poverty Clock announced Nigeria to be the poverty capital of the world, and over $40 \%$ of her citizens lived below the poverty line. Also,large percentage of the Nigerian population live on daily income [108] and have almost no savings to act as a financial buffer during the lockdown [9]. For instance, in families where the man and the wife are market sellers, with the lockdown restrictions and closure of markets, such families will barely have enough to feed the family. Thus, it becomes a burden for them to provide a sufficient flow of vital supplies should any member contract COVID-19; they may not even have enough space at home for isolation. Another big concern here is if a hungry COVID-19 patient will accept to stay hungry in isolation, or rather go out into the society to look out for his stomach. Furthermore, the governments of some foreign nations were providing financial support and free meals to the citizens to help ease the hardship caused by COVID-19 [109,110], but this is not exactly the case in Nigeria. So, it becomes difficult for patients in Nigeria to self-isolate at home in the midst of hunger, especially when the patient is the breadwinner of his/her family. Moreover, the negligence of the government and the healthcare workers in the provision of an adequate supply of food and medical attention for those in isolations [111] may further discourage infected individuals from calling out for medical interventions to be isolated.

Sadly, the failure to comply with thegovernment directives on the wearing of facemask and remaining in isolation when ill is also a huge problem. The CDC recommends the use of facemasks by everyone in public places and staying at home when one is ill [112]. However, in Nigeria, facemasks are mainly bought for the purpose of avoiding police arrest, rather than prevention of COVID-19. Also, most persons put their masks below their jaws, rather than cover the mouth and nose. Hence, if one is infected with COVID-19, there is a high tendency for spread to people within his/her vicinity (such as members of the household and visitors), who would also take it to their homes to compound the problem the more.

Nevertheless, despite the high level of awareness of the disease in Nigeria as reported by Azuonwu, et al., [113], the high level of illiteracy and lack of exposure and enlightenment in the country $[114,115]$ has only made matters worse. Till date, many Nigerians as a result of fake news and mistrust in the government programs and policies do not believe COVID-19 is real, while some believe the governments are only using the pandemic as an avenue to steal from the already struggling economy [116]. There is the tendency that such individuals, even if confirmed to be COVID-19 positive, would refuse to willingly self-isolate especially when asymptomatic, and this also poses a threat to the health of people living around. Also, Nigerians have been advised to lodge and isolate in hotels when ill, and when home isolation is not feasible [117]. In a country characterized by low standards of living, low-income earners and daily traders, the government has not made any provision for free hotel bills. Hence, individuals may shy away from hotel isolation as they may not be able to foot the bills to accommodate those who cannot pay to stay safe. Besides, some asymptomatic COVID-19 confirmed patients may selfisolate in hotels without revealing their health status or why they are lodging. This poses a public health risk to everyone within the hotel vicinity as there are no testing centres in the hotels to diagnose the visitors. Eventually, when they recover and leave, the innocent hotel management may not conduct proper disinfection of the place before another healthy subject moves in, hence exposing the new customers to the viral particles which may have been deposited in the room and beddings. Worse off, is the issue of some patients opting for self-medication upon the onset of symptoms rather than calling out for medical attention for proper care.

Another setback peculiar to Nigeria is the issue of bad roads and traffic congestion across the major cities of the country [118]. Also, some towns in the rural areas of the country are not motorable, while some not very popular. These factors could affect emergency response should a patient present with sudden deterioration in health while isolating at home. The lack of a reliable database of the inhabitants of the country, and a corresponding lack of a reliable Global Positioning System (GPS) based tracking system [119,120] 


\section{Open Access Journal of Microbiology \& Biotechnology}

may also become a barrier to quick interventions for cases of emergency evacuation of patients on home treatment. Nonetheless, the inadequate availability of disease response logistics (including such essentials as cars, ambulances, etc.) for easy and prompt visitation and evacuation of patients when necessary poses a challenge. The lack of sufficient supply of manpower (healthcare workers) to take care of the various regions of the country is as well, a major setback as there are bound to be delays in visitations and emergency responses. It is also worthy of note that stigma may ensue from the frequent visit of a patient's residence, by the NCDC health team with their buses bold written COVID 19 emergency response team, during and after treatment as the members of the neighborhood may continue to distance themselves from the patient's household even after patient recovery.

Nonetheless and moving further, there is massive lack of adequate testing capacity in the country [13]. Nigeria, with a population size of roughly 200 million people [121], has conducted only 436,231 COVID-19 tests as of 8 September 2020 [10]. The lack of an active community testing strategy to uncover asymptomatic carriers implies that there may be a considerably high number of untested COVID-19 patients moving freely in the streets and transmitting the infection freely unchecked, thereby undermining the efforts of the healthcare workers. Also, the majorities of COVID-19 tests in Nigeria are conducted in the popular cities of the country, and are based on symptomatic rumours and calls from infected patients; whereas, remote areas and villages hardly have access to tests, and hence, are subjected to an increased risk of severe to critical COVID-19 outcomes. In the absence of testing, it is almost impossible for asymptomatic patients to know they are ill and self-isolate at home. Additionally, the poor sanitary standards in Nigeria [122,123], strongly back by the citizens with the saying "doti no dey kill African man" (meaning "dirt does not kill an African") is also a huge challenge in the battle against COVID-19 [124]. Many Nigerians already have this mentality, and these persons are almost not likely to adhere to the government directives on sanitation and hygiene to prevent the spread of the illness. Hence, they also pose a threat to public health. Besides, the issue of poor COVID-19 wastes management at home due to ignorance cannot be overlooked.

Notwithstanding, frontline health workers in the country have consistently lamented the lack of an adequate supply of personal protective equipment (PPE) for their use on duty. This has left them dangerously ill-equipped in their bid to provide appropriate care for COVID-19 patients in different hospitals in the country $[125,126]$. Nevertheless, as of $2^{\text {nd }}$, June 2020, not less than 812 healthcare workers across the country were reportedly infected with the disease [57]. This also puts the health care workers, their friends, relations and household members at risk. Another consequence of this is fear, insecurities, as well as avoidance syndrome [127]. In addition, the high level of insurgency, militancy and banditry in the country [128] also poses a security risk to the health care workers and caregivers as they have to visit patients in their homes to administer care. This is a cause for concern, especially when the patient(s) live in remote and/or isolated areas with no clear cut detailed address for prompt action tracking during supposedly emergency.

The epicenter of the disease in Nigeria includes such states as Lagos, FCT, Rivers, Oyo and Edo [10]. The high prevalence within these states can be attributed to their large population sizes and human contact traffic, as well as their high industrial and commercial activities. As a result, there is a high likelihood of imported cases by experts and hustlers (especially in the oil and gas, as well as other business sectors) whose restrictions are not strict and their businesses not locked down. The migration of such persons into the states increases the risk of community transmission as they continue to mix-up with the populace, even in the midst of poor testing capacity in the country [13], these implied that transmissions may not be detected early enough, leading to escalation of increasing number of unknown positive cases. However, the low prevalence in some states such as Kogi, Yobe, Zamfara, Cross River and Kebbi may probably be attributed to their relatively smaller population sizes, comprising of mainly civil servants, whose jobs are mostly based within the states capital cities. Also, the low level of industrial and commercial activities in these states promotes less inflow of experts and hustlers who may probably carry the disease asymptomatically for a long time. In addition, the major states of the country are where large number of elites resides with the large population sizes, it is no surprise that the highest numbers of deaths are recorded in these states, as the large populations would likely comprise of greater number of susceptible individuals and those with underlying health conditions. Impressively, there is a very encouraging level of recoveries of COVID-19 patients, and subsequent discharge from hospitals. Data from NCDC showed that out of the 58,647 confirmed cases reported as of 30 September $2020,49,937$ have recovered from the illness and have been discharged from the hospitals, and a minimal case fatality rate of $1.9 \%$ was recorded [10]. However, if home-based treatment/care is introduced without caution and adequate monitoring, the substandard living conditions of the people in the country may cause an alarming deterioration in the level of progress achieved from hospital-based treatment/ care.

In view of the above forgoing, it is crystal clear that the country is currently lacking evidence-based research outcome, Quality Control and Quality Assurance mechanism to x-ray and analyse the workability and sustainability of the 


\section{Open Access Journal of Microbiology \& Biotechnology}

modalities adopted by other nations, especially European countries, UK and USA for fighting COVID-19 pandemic, so as to determine how effective these modalities and strategies would be in Nigeria, given our difference in behavioural pattern, sociopolitical outcome, religious and cultural practices. Thus, while the modalities being adopted by other countries may be proving beneficial to them and functioning well, they are not a one-size-fits-all solution to the global problems of COVID-19 in other countries, especially in resource limited communities in Africa.

\section{Conclusion and Recommendations}

The lack of evidence-based research on the suitability of policies adopted in foreign countries to fight COVID-19 pandemic, before implementing them in Nigeria may have some negative effects on the lives of the people in the country, given that our sociocultural, political, behavioural, religious and economic practices are quite different from those of the Western world. Hence, adopting these policies without prior investigation of how it will work and affect the people of Nigeria. This may either work for us or against us, despite working fine in the other countries, hence, instead of copying and pasting the strategies of other countries, we recommend the following:

> Evidence-based research, as well as quality control and quality assurance schemes, should be conducted on the strategies being implemented in other countries in order to determine how suitable and effective, they would be if we must apply them here.

$>$ The lifestyles and cultures of the populace from different region of Nigeria should be evaluated critically to determine which strategy of management of COVID-19 would best suit the socio-cultural, political, religious and economic demands of citizens within the country, given our huge gap in cultural and religious differences and variations

$>$ More treatment and testing centers should be provided to reduce the risk of home treatment that may probably breed community transmission.

$>$ The provision of low cost housing scheme for the weak and poor populace would help to reduce the problem of lack of housing in the country.

$>$ There is urgent need to empower the citizens through wealth creation opportunities and provision of basic amenities that would promote public health outcome of the citizens

\section{References}

1. Zhu N, Zhang D, Wang W, Li X, Yang B, et al. (2019) A Novel Coronavirus from Patients with Pneumonia in China. N Engl J Med 382(8): 727-733.
2. WHO (2020) Coronavirus disease 2019 (COVID-19): Situation Report - 91. World Health Organisation.

3. Chakraborty I, Maity P (2020) COVID-19 outbreak: Migration, effects on society, global environment and prevention. Sci Total Environ 728: 138882.

4. Chan JF, Kok KH, Zhu Z, Chu H, To KK, et al. (2020) Genomic characterization of the 2019 novel humanpathogenic coronavirus isolated from a patient with atypical pneumonia after visiting Wuhan. Emerg Microbes Infect 9(1): 221-236.

5. Li X, Wang W, Zhao X, Zai J, Zhao Q, et al. (2020) Transmission dynamics and evolutionary history of 2019-nCoV. J Med Virol 92(5): 501-511.

6. WHO (2020) Director-General's opening remarks at the media briefing on COVID-19 - 11 March 2020. World Health Organisation.

7. WHO (2020) COVID-19 cases top 10000 in Africa. World Health Organisation.

8. UNESCO (2020) Socio-economic and cultural impacts of covid-19 on Africa: UNESCO responses. United Nations Educational, Scientific and Cultural Organization.

9. Kalu B (2020) COVID-19 in Nigeria: a disease of hunger. Lancet Respir Med 8(6): 556-557.

10. (2020) COVID-19 Nigeria. Nigeria Centre for Disease Control.

11. Anudu 0, Bassey J (2020) Nigeria faces acute job losses as COVID-19 incapacitates employers.

12. Africa News (2020) Coronavirus - Nigeria: Citizens in doubt of COVID-19 should take precaution in their daily activities - Dr Olorunnimbe Mamora.

13. Azuonwu O, Ama-Okachi BC, Ahiakwo C (2020) Failed healthcare system and poor leadership outcome: A huge public health challenge towards the management of COVID-19 pandemic in Sub-Saharan Africa. OSP J Health Car Med 1 HCM-1-106.

14. Onwuzoo A (2020) Nigeria can't beat COVID-19 with patients fleeing isolation centres. Punch Healthwise.

15. Omondi J (2020) Nigeria extends second phase nationwide COVID-19 lockdown by four weeks.

16. Orjinmo N (2020) Coronavirus lockdown: Nigerians cautious as restrictions eased in Lagos and Abuja.

17. Aveyard H (2010) Doing a literature review in health and social care, $2^{\text {nd }}(E d n)$, Open University Press, 


\section{Open Access Journal of Microbiology \& Biotechnology}

Maidenhead, UK.

18. The World Bank (2020) The Global Economic Outlook During the COVID-19 Pandemic: A Changed World.

19. WHO (2020) Coronavirus disease (COVID-19) pandemic. World Health Organisation.

20. WHO (2020) Coronavirus. World Health Organisation.

21. Fehr AR, Perlman S (2015) Coronaviruses: an overview of their replication and pathogenesis. Methods Mol Biol 1282: 1-23.

22. Wu A, Peng Y, Huang B, Ding X, Wang X, et al. (2020) Genome composition and divergence of the novel coronavirus (2019-nCoV) originating in China. Cell Host Microbe 27(3): 325-328.

23. Yin Y, Wunderink RG (2018) MERS, SARS and other coronaviruses as causes of pneumonia. Respirology 23(2): 130-137.

24. Zhou P, Yang XL, Wang XG, Hu B, Zhang L, et al. (2020) A pneumonia outbreak associated with a new coronavirus of probable bat origin. Nature 579(7798): 270-273.

25. Hui DS, Azhar EI, Madani TA, Ntoumi F, Kock R, et al. (2020) The continuing 2019-nCoV epidemic threat of novel coronaviruses to global health - the latest 2019 novel coronavirus outbreak in Wuhan, China. Int J Infect Dis 91: 264-266.

26. WHO (2020) Coronavirus disease (COVID-19): Data as received by WHO from national authorities, as of 27 September 2020, 10 am CEST. World Health Organisation.

27. Zimmermann P, Curtis N (2020) Coronavirus Infections in Children Including COVID-19: An Overview of the Epidemiology, Clinical Features, Diagnosis, Treatment and Prevention Options in Children. Pediatr Infect Dis J 39(5): 355-368.

28. Dong Y, Mo X, Hu Y, Qi X, Jiang F, etal. (2020) Epidemiology of COVID-19 Among Children in China. Pediatrics 145(6): e20200702.

29. WHO (2020) Report of the WHO-China joint mission on coronavirus disease 2019 (COVID-19). World Health Organization.

30. Streng A, Hartmann K, Armann J, Berner R, Liese JG (2020) COVID-19 in hospitalized children and adolescents. Monatsschr Kinderheilkd 21: 1-12.

31. Dong XC, Li JM, Bai JY, Liu ZQ, Zhou PH, et al. (2020) The epidemiological characteristics of an outbreak of
2019 novel coronavirus diseases (COVID-19) in China. Zhonghua Liu Xing Bing Xue Za Zhi 41(2): 145-151.

32. (CDC) Centers for Disease Control and Prevention (2020) Coronavirus Disease 2019 in Children - United States, February 12-April 2, 2020. MMWR Morb Mortal Wkly Rep 69(14): 422-426.

33. Garazzino $S$, Montagnani $C$, Donà $D$, Meini $A$, Felici E, et al. (2020) Multicentre Italian study of SARS-CoV-2 infection in children and adolescents, preliminary data as at 10 April 2020. Euro Surveill 25(18): 2000600.

34. Zaigham M, Andersson 0 (2020) Maternal and perinatal outcomes with COVID-19: A systematic review of 108 pregnancies. Acta Obstet Gynecol Scand 99(7): 823-829.

35. Karimi-Zarchi M, Neamatzadeh H, Dastgheib SA, Abbasi H, Mirjalili SR, et al. (2020) Vertical Transmission of Coronavirus Disease 19 (COVID-19) from Infected Pregnant Mothers to Neonates: A Review. Fetal Pediatr Pathol 39(3): 246-250.

36. Elshafeey F, Magdi R, Hindi N, Elshebiny M, Farrag N, et al. (2020) A systematic scoping review of COVID-19 during pregnancy and childbirth Int J Gynaecol Obstet 150(1): 47-52.

37. Sutton D, Fuchs K, D'Alton M, Goffman D (2020) Universal Screening for SARS-CoV-2 in Women Admitted for Delivery. N Engl J Med 382(22): 2163-2164.

38. Breslin N, Baptiste C, Gyamfi-Bannerman C, Miller R, Martinez R, et al. (2020) Coronavirus disease 2019 infection among asymptomatic and symptomatic pregnant women: two weeks of confirmed presentations to an affiliated pair of New York City hospitals. Am J Obstet Gynecol MFM 2(2): 100118.

39. Wu X, Sun R, Chen J, Xie Y, Zhang S, et al. (2020) Radiological findings and clinical characteristics of pregnant women with COVID-19 pneumonia. Int J Gynaecol Obstet 150(1): 58-63.

40. SVT News (2020) The hospital coronates all pregnant women at birth-seven percent infected.

41. Schwartz DA (2020) An Analysis of 38 Pregnant Women with COVID-19, Their Newborn Infants, and MaternalFetal Transmission of SARS-CoV-2: Maternal Coronavirus Infections and Pregnancy Outcomes. Arch Pathol Lab Med.

42. Penfield CA, Brubaker SG, Limaye MA, Lighter J, Ratner AJ, et al. (2020) Detection of severe acute respiratory syndrome coronavirus 2 in placental and fetal membrane samples. Am J Obstet Gynecol MFM 2(3): 100133. 


\section{Open Access Journal of Microbiology \& Biotechnology}

43. Zamaniyan M, Ebadi A, Aghajanpoor S, Rahmani Z, Haghshenas M, et al. (2020) Preterm delivery, maternal death, and vertical transmission in a pregnant woman with COVID-19 infection. Prenat Diagn.

44. Zeng H, Xu C, Fan J, Tang Y, Deng Q, et al. (2020) Antibodies in Infants Born to Mothers With COVID-19 Pneumonia. JAMA 323(18): 1848-1849.

45. Dong L, Tian J, He S, Zhu C, Wang J, et al. (2020) Possible Vertical Transmission of SARS-CoV-2 From an Infected Mother to Her Newborn. JAMA 323(18): 1846-1848.

46. Wang S, Guo L, Chen L, Liu W, Cao Y, et al. (2020) A Case Report of Neonatal 2019 Coronavirus Disease in China. Clin Infect Dis 71(15): 853-857.

47. Chen L, Li Q, Zheng D, Jiang H, Wei Y, et al. (2020) Clinical Characteristics of Pregnant Women with Covid-19 in Wuhan, China. N Engl J Med 382(25): e100.

48. Chen H, Guo J, Wang C, Luo F, Yu X, et al. (2020) Clinical characteristics and intrauterine vertical transmission potential of COVID-19 infection in nine pregnant women: a retrospective review of medical records. Lancet 395(10226): 809-815.

49. Groß R, Conzelmann C, Müller JA, Stenger S, Steinhart $\mathrm{K}$, et al. (2020) Detection of SARS-CoV-2 in human breastmilk. Lancet 395(10239): 1757-1758.

50. (2020) Epidemiology of COVID-19. European Centre for Disease Prevention and Control.

51. Nguyen LH, Drew DA, Joshi AD, Guo C-G, Ma W, et al. (2020) Risk of COVID-19 among frontline healthcare workers and the general community: a prospective cohort study. medRxiv 5(9): E475-E483.

52. Liu Y, Yan LM, Wan L, Xiang TX, Le A, et al. (2020) Viral dynamics in mild and severe cases of COVID-19. Lancet Infect Dis 20(6): 656-657.

53. Riccardo F, Ajelli M, Andrianou X, Bella A, Del Manso M, et al. (2020) Epidemiological characteristics of COVID-19 cases in Italy and estimates of the reproductive numbers one month into the epidemic. medRxiv.

54. Liu Y, Gayle AA, Wilder-Smith A, Rocklöv J (2020) The reproductive number of COVID-19 is higher compared to SARS coronavirus. J Travel Med 27(2): 021.

55. (2020) Epidemic update and risk assessment of 2019 Novel Coronavirus. Chinese Center for Disease Control and Prevention.

56. Backer JA, Klinkenberg D, Wallinga J (2020) Incubation period of 2019 novel coronavirus (2019-nCoV) infections among travellers from Wuhan, China, 20-28 January 2020. Euro Surveill 25(5): 2000062.

57. Adejoro L (2020) 812 healthcare workers infected with COVID-19 -NCDC.

58. WHO (2020) Coronavirus disease 2019 (COVID-19): Situation report - 53. World Health Organization.

59. Nazario B (2020) What is community transmission?

60. Anyaogu I (2020) Rising community transmission of COVID-19 strengthens case for social distancing.

61. CDC (2020) Using an epi curve to determine mode of spread. Centers for Disease Control and Prevention.

62. Frellick M (2020) Risk of Secondary COVID-19 Transmission Low in Most Settings.

63. Zhang W, Cheng W, Luo L, Ma Y, Xu C, et al. (2020) Secondary transmission of Coronavirus disease from presymptomatic persons, China. Emerging Infectious Diseases 26(8): 1924-1926.

64. (2020) Assessing risk factors for severe COVID-19 illness. Centers for Disease Control and Prevention.

65. (2020) People with certain medical conditions. Centers for Disease Control and Prevention.

66. Mhango M, Dzobo M, Chitungo I, Dzinamarira T (2020) COVID-19 risk factors among health workers: A rapid review. Safety and Health at Work 11(3): 262-265.

67. WHO (2020) Laboratory testing for coronavirus disease (COVID-19) in suspected human cases. World Health Organization.

68. To KK, Tsang OT, Leung WS, Tam AR, Wu TC, et al. (2020) Temporal profiles of viral load in posterior oropharyngeal saliva samples and serum antibody responses during infection by SARS-CoV-2: an observational cohort study. The Lancet Infectious diseases 20(5): 565-574.

69. Corman VM, Landt O, Kaiser M, Molenkamp R, Meijer A, et al. (2020) Detection of 2019 novel coronavirus (2019-nCoV) by real-time RT-PCR. Euro Surveill 25(3): 2000045.

70. Chu D, Pan Y, Cheng S, Hui K, Krishnan P, et al. (2020) Molecular Diagnosis of a Novel Coronavirus (2019$\mathrm{nCoV}$ ) Causing an Outbreak of Pneumonia. Clin Chem 66(4): 549-555.

71. Russo A, Minichini C, Starace M, Astorri R, Calò F, et al. (2020) Current status of laboratory diagnosis for 


\section{Open Access Journal of Microbiology \& Biotechnology}

covid-19: A narrative review. Infect Drug Resist 13: 2657-2665.

72. Kim H, Hong H, Yoon SH (2020) Diagnostic Performance of CT and Reverse Transcriptase Polymerase Chain Reaction for Coronavirus Disease 2019: A Meta-Analysis. Radiology 296(3): E145-E155.

73. Xiao AT, Tong YX, Zhang S (2020) False negative of RTPCR and prolonged nucleic acid conversion in COVID-19: Rather than recurrence. J Med Virol.

74. Wang X, Yao H, Xu X, Zhang P, Zhang M, et al. (2020) Limits of Detection of 6 Approved RT-PCR Kits for the Novel SARS-Coronavirus-2 (SARS-CoV-2). Clin Chem 66(7): 977-979.

75. Li Y, Yao L, Li J, Chen L, Song Y, et al. (2020) Stability issues of RT-PCR testing of SARS-CoV-2 for hospitalized patients clinically diagnosed with COVID-19. J Med Virol 92(7): 903-908.

76. Baek YH, Um J, Antigua KJC, Park JH, Kim Y, et al. (2020) Development of a reverse transcription-loop-mediated isothermal amplification as a rapid early-detection method for novel SARS-CoV-2. Emerg Microbes Infect 9(1): 998-1007.

77. Huang WE, Lim B, Hsu CC, Xiong D, Wu W, et al. (2020) RT-LAMP for rapid diagnosis of coronavirus SARS-CoV-2. Microbial Biotechnology 13(4): 950-961.

78. Castro R, Luz PM, Wakimoto MD, Veloso VG, Grinsztejn B, et al. (2020) COVID-19: a meta-analysis of diagnostic test accuracy of commercial assays registered in Brazil. Braz J Infect Dis 24(2): 180-187.

79. Cheng MP, Papenburg J, Desjardins M, Kanjilal S, Quach C, et al. (2020) Diagnostic Testing for Severe Acute Respiratory Syndrome-Related Coronavirus 2: A Narrative Review. Ann Intern Med 172(11): 726-734.

80. Yang T, Wang YC, Shen CF, Cheng CM (2020) Point-of-Care RNA-Based Diagnostic Device for COVID-19. Diagnostics (Basel) 10(3): 165.

81. Li Z, Yi Y, Luo X, Xiong N, Liu Y, et al. (2020) Development and clinical application of a rapid IgM-IgG combined antibody test for SARS-CoV-2 infection diagnosis. J Med Virol.

82. WHO (2020) Clinical management of COVID-19. World Health Organisation.

83. Greenhalgh T, Koh G, Car J (2020) Covid-19: a remote assessment in primary care. 368: $\mathrm{m} 1182$.
84. WHO (2009) Dengue guidelines for diagnosis, treatment, prevention and control. Geneva. World Health Organization.

85. WHO (2015) Guidelines for the treatment of malaria, $3^{\text {rd }}$ (Edn.), World Health Organization, Geneva.

86. WHO (2017) Guidelines for treatment of drugsusceptible tuberculosis and patient care. World Health Organization, Geneva.

87. Duncan H, Hutchison J, Parshuram CS (2006) The Pediatric Early Warning System score: a severity of illness score to predict urgent medical need in hospitalized children. J Crit Care 21(3): 271-278.

88. WHO (2018) WHO-ICRC Basic Emergency Care: Approach to the acutely ill and injured. Geneva. World Health Organization.

89. WHO (2016) Paediatric emergency triage, assessment and treatment. World Health Organization, pp: 88.

90. WHO (2016) Oxygen therapy for children: a manual for health workers. World Health Organization, pp: 66.

91. Schultz MJ, Dunser MW, Dondorp AM, Adhikari NK, Iyer $S$, et al. (2017) Current challenges in the management of sepsis in ICUs in resource-poor settings and suggestions for the future. Intensive Care Med 43(5): 612-624.

92. Weiss SL, Peters MJ, Alhazzani W, Agus M, Flori HR, et al. (2020) Surviving Sepsis Campaign International Guidelines for the Management of Septic Shock and Sepsis-Associated Organ Dysfunction in Children. Pediatr Crit Care Med 21(2): e52-e106.

93. WHO (2020) Home care for patients with suspected novel coronavirus COVID-19 infection presenting with mild symptoms, and management of their contacts: Interim guidance. World Health Organization.

94. (2020) Interim Guidance for Implementing Home Care of People Not Requiring Hospitalization for Coronavirus Disease 2019 (COVID-19), Centers for Disease Control and Prevention.

95. Government of Canada (2020) Updated: Public health management of cases and contacts associated with coronavirus disease 2019 (COVID-19).

96. (2020) Interim guidelines for home care of confirmed covid-19 cases. Nigeria Centre for Disease Control.

97. Leicester J, Parra A (2020) Lifting lockdown? Against coronavirus, no one size fits all. 


\section{Open Access Journal of Microbiology \& Biotechnology}

98. Pison G (2020) Why African families are larger than those of other continents.

99. Eurostat (2020) Fertility statistics.

100. Eurostat (2020) Household composition statistics.

101. Doepke M, Kindermann F (2016) Why European women are saying no to having (more) babies.

102. Olito F (2019) Utah has the highest number of children in their families. Here's the average number of kids per family in every state.

103. Duffin E (2019) Average number of people per family in the United States from 1960 to 2019.

104. Duffin E (2020) Average number of own children under 18 in families with children in the United States from 1960 to 2019.

105. Plecher H (2020) Nigeria: Fertility rate from 2008 to 2018.

106. Akinbobola T, Saibu OM (2004) Income Inequality, Unemployment, and Poverty in Nigeria: a Vector Autoregressive Approach.

107. Voa News (2018) Nigeria Struggles against Unemployment, Extreme Poverty.

108. Azuonwu 0, Agba PC, Ahiakwo C, Azuonwu G (2020) Epidemiology dynamics and pattern of emerging drawbacks promoting community based transmission of COVID 19 pandemic virus in Nigeria: Lessons from the advanced communities strategy. Journal of Current Trends in Nursing \& Health Care 1: 104.

109. France 24 (2020) France rolls out initial €45 billion package to help struggling companies.

110. The Guardian (2020) UK government to pay $80 \%$ of wages for those not working in coronavirus crisis.

111. Adejoro L (2020) COVID-19 patients need good diet to beat virus-Nutritionists.

112. (2020) Considerations for wearing masks. Centers for Disease Control and Prevention.

113. Azuonwu O, Ihua N, Ahiakwo C, Agala V (2020) Investigation of the level of public awareness outcome of COVID-19 pandemic among Nigerians. Journal of
Virology Research \& Reports 1(1): 1-8.

114. Yusuf MA, Ladan B, Idris UA, Halilu A (2013) Comparative study of the state of literacy in Nigeria and Cuba. European Scientific Journal 9(19): 34-44.

115. United Nations Educational, Scientific and Cultural Organization (2012) High level International Round Table on Literacy "Reaching the 2015 Literacy Target: Delivering on the promise".

116. Adegoke Y (2020) Coronavirus in Nigeria: Inside a Lagos coronavirus ward.

117. Nwagbara C (2020) COVID-19: Hotels.ng partners others to provide self-isolation centres for Nigerians.

118. Ukpata J0, Etika AA (2012) Traffic congestion in major cities of Nigeria. International Journal of Engineering and Technology 2(8): 1433-1438.

119. Falaju J, Omolaoye S (2019) 'Lack of database worsening Nigeria's humanitarian crisis'.

120. Lekan AJ (2011) Improving national security using gps tracking system technology. Mediterranean Journal of Social Sciences 2(5): 75-85.

121. World Population Review (2020) Nigeria Population 2020 (Live).

122. Diyaolu A (2016) Lagos and poor sanitary standards.

123. UNICEF (2018) Water, Sanitation and Hygiene.

124. Okafor J (2019) The science behind "doti no dey kill African man"-and what can go wrong.

125. Okunola A (2020) 5 Challenges Facing Health Care Workers in Nigeria as they Tackle COVID-19.

126. Onwuzoo A (2020) Fighting a pandemic without PPE.

127. Azuonwu 0, Reuben AA, Elekwachi AB (2020) Potential Impact of COVID-19 Pandemic on the SocioEconomic Situations in Nigeria: A Huge Public Health Risk of unprecedented Concern. J Qual Healthcare Eco 3(4): 000175.

128. Okoli CA (2019) Kidnapping for ransom has become Nigeria's latest security problem. 